\title{
Update on Clinical Detection Methods for Noncavitated Fissure Caries
}

\author{
Erum Zain ${ }^{1}$, Hooi P Chew $^{2}$
}

\begin{abstract}
Aim:This review presents an updated overview and evidences on diagnostic performances of clinical detection methods to detect noncavitated fissure caries.

Background: The current body of evidence regarding the progression and arrest of dental caries has made its early detection, risk assessment, and minimally invasive management the standard of care today. Hence, its diagnosis should ideally comprise of both detection and severity measurement in the form of lesion depth, demineralization severity, and mineral density distribution. A combination of this information is essential for clinicians to make informed decisions about the management of the disease process. To address the above needs, a plethora of clinical caries detection systems are available and most demonstrate differing diagnostic performance for approximal and fissure caries. In this review, the available systems are categorized based broadly upon their mechanism of actions, under the categories of conventional, nonoptical, and optical methods. This review article sought to present the published evidence of these systems in detecting noncavitated fissure caries. As far as possible, evidence from systematic reviews were presented. In cases where systematic reviews were not available, preference had been given to the present evidence from in vitro and in vivo studies that had employed histology as the validation method.

Conclusion: Based on the current evidences and reviews, except for optical coherence tomography, most devices are only able to detect and determine either lesion depth or demineralization severity but not both.

Clinical significance: In order to be able to gather necessary information to formulate a treatment plan for noncavitated fissure caries and monitor its efficacy, routine visual assessment will need to be supplemented by another quantification-enabled detection device that had demonstrated reasonably high sensitivity and specificity. Current evidences seem to indicate that photothermal radiometry, near-infrared transillumination, and optical coherence tomography are systems that had demonstrated such capabilities.

Keywords: Early enamel caries, Electrical conductance and impedance, FOTI, Laser fluorescence, NIR transillumination, Noncavitated fissure caries, Optical coherence tomography, Photothermal radiometry and modulated luminescence, Sensitivity and specificity, Visual detection.

World Journal of Dentistry (2020): 10.5005/jp-journals-10015-1687
\end{abstract}

\section{INTRODUCTION}

Dental caries continues to be a major health problem, ${ }^{1}$ varying from subsurface enamel demineralization to extensive dentinal involvement clinically. ${ }^{2,3}$ A systematic review ${ }^{1}$ in 2015 on global burden of untreated dental caries drew attention of policy makers regarding predictable rise in untreated dental caries due to increase in population and teeth longevity and decline in the prevalence of tooth loss from 1990 to 2010. Another systematic analysis in 2013 on the global burden of oral conditions in 1990-2010 made it evident that the burden of untreated caries is tipping from children to adults and is most prevalent in ages 6, 25 and 70 years.

The progression of enamel caries lesion has dramatically changed during past decades. ${ }^{5,6}$ The use of fluoride and other preventive interventions has slowed down the progression of lesion activity of noncavitated lesions by preventing the initiation and reversing early signs of demineralization and preserving the tooth structure. ${ }^{7}$ It is hence widely accepted that detection of noncavitated caries lesions may provide health and economic advantages through timely implementation of preventive regimes by reversing or arresting it, and reduces treatment time, cost, and patient sufferings. ${ }^{8,9}$ Although evidence supports that recording lesion at the cavitated stage is no longer accepted, ${ }^{10}$ detection of subtle and early changes on the surfaces of pits and fissures is challenging due to the complex morphology. ${ }^{9}$
${ }^{1}$ Department of Restorative Dentistry, Faculty of Dentistry, University of Malaya, Kuala Lumpur, Malaysia; Department of Restorative Dentistry, Faculty of Dentistry, SEGi University, Selangor, Malaysia

${ }^{2}$ Department of Restorative Dentistry, Faculty of Dentistry, University of Malaya, Kuala Lumpur, Malaysia; Department of Restorative Sciences, School of Dentistry, University of Minnesota, Minnesota, USA Corresponding Author: Hooi P Chew, Department of Restorative Dentistry, Faculty of Dentistry, University of Malaya, Kuala Lumpur, Malaysia; Department of Restorative Sciences, School of Dentistry, University of Minnesota, Minnesota, USA, Phone: +1 (612)4044035, e-mail: chew0014@umn.edu

How to cite this article: Zain E, Chew HP. Update on Clinical Detection Methods for Noncavitated Fissure Caries. World J Dent 2020;11(1):81-88.

Source of support: High Impact Research MoE Grant UM.C/625/1/HIR/ MoE/DENT/11 from the Ministry of Education, Malaysia

Conflict of interest: None

Pits and fissures caries lesions contribute $88 \%$ of caries experienced in schoolchildren in the United States. ${ }^{11}$ Although pits and fissure have not been found to be ultrastructurally cariesprone, the inaccessible areas within the fissures provide stagnation sites for the accumulation of dental plaque. These protected areas are sheltered from mechanical cleaning and oral functions such as toothbrushing and mastication, thus making these areas more at risk to caries development. ${ }^{12}$ Therefore, accurate and reliable 
clinical diagnostic techniques are important to support diagnosis and management of these noncavitated lesions in clinical settings.

A good detection method should be accurate, valid, and reliable. ${ }^{13,14}$ Validity determines if the test is truly able to record what it purports to record and reliability determines whether the test can be used by different examiners to produce identical results. ${ }^{15}$ The accuracy of a diagnostic test is its ability to differentiate among individuals with the disease from those without it. The performance of a diagnostic test is also assessed by measures such as sensitivity, specificity, likelihood ratios, and predictive values. ${ }^{16} \mathrm{~A}$ Cochrane diagnostic test accuracy review ${ }^{16}$ reported that the accuracy of a diagnostic test is dependent upon the diagnostic threshold and the estimates of sensitivity and specificity vary dramatically if the diagnostic threshold is altered. Presence of variance, inconsistency, and disagreement is expected to occur in new test systems and these are referenced against a "gold" standard. Hence, selection of the reference standard and setting its diagnostic threshold forms an integral part in validating the accuracy of a new diagnostic test.

In the case of caries detection, the threshold scheme that is most frequently used was described by the World Health Organization, ${ }^{17}$ which consists of four levels. The $D_{2}$ (histological caries extending beyond the outer half but confined to the enamel) and $D_{3}$ (histological dentinal caries limited to the outer half of the dentin thickness) levels are the two most clinically pertinent and therefore the levels most applied in detection performance studies.

Many systematic reviews ${ }^{18-22}$ have recently been published on caries detection methods with focused research questions such as the performance of one particular diagnostic or detection method for either primary or secondary caries. The objective of this paper is thus to present the existing evidences of the plethora of clinical detection methods available specifically for primary noncavitated fissure caries.

\section{Conventional Methods}

\section{Visual and Tactile}

Clinical detection of noncavitated caries by convention is predominantly performed by visual or visual and tactile inspection ${ }^{23}$ due to its relatively simple technique and low cost. Clinically, noncavitated fissure caries detection by visual examination is achieved by air drying the tooth surface for a short interval, replacing water with air and hence altering the refractive index and the optical properties of the enamel. The change in refractive indices makes the more porous caries lesion appear chalky and opaque. ${ }^{24}$ This technique has been reported to have high specificity range of $0.91-0.93$ but moderate sensitivity range of $0.75-0.79$, for detection of initial fissure caries lesions, ${ }^{18}$ with the latter attributed mainly to the use of subjective and qualitative features such as color, texture, and roughness as the criteria for diagnosis. ${ }^{25}$

The visual detection system such as the International Caries Detection and Assessment System (ICDAS) has validated its criteria for diagnosis of caries lesions against histology. The ICDAS code 1 is used for the noncavitated lesion that is visually detectable only after air dried, and histologically, its demineralization is limited to the outer $50 \%$ of the enamel. The ICDAS code 2 caries lesions are described to present with distinct visual change and their demineralization is shown to be between $50 \%$ of the enamel and outer third of the dentin. ${ }^{26} \mathrm{~A}$ study by Jablonski-Momeni et al. ${ }^{27}$ in 2008 reported high sensitivity (mean $=0.89$ ) but low specificity (mean $=0.52$ ) for this system at the cutoff between code 0 and 1. However, this low specificity may not result in the detrimental clinical outcome. It is contended that in the most extreme situation, treatment for such cases would be prevention to a sound site, which will be beneficial in high-risk patients. However, a lower sensitivity (mean $=0.69$ ) and higher specificity (mean $=0.82$ ) was demonstrated at the cutoff between code 1 and 2 . Another study ${ }^{14}$ reported optimum sensitivity and specificity of 0.95 and 0.85 (cutoff at ICDAS 1-2), respectively, for noncavitated fissure caries.

The ICDAS visual method was reported with moderate to high intra- and interexaminer reproducibility (weighted kappa values of $0.76-0.93^{14}$ and $\left.0.62-0.83\right)^{27}$ for noncavitated fissure caries. It is worth noting though that this high reproducibility was the result of meticulous training and calibration sessions. Nevertheless, it is still very challenging to differentiate subtle changes in early lesions and the most common error (18.5\%) being code 1 being mistaken for code 2 or vice versa followed by code 0 being mistaken for code 1 or vice versa (14\%). ${ }^{14}$ Presence of fluorosis, stained fissures, or developmental defects can also be mistaken for caries lesions, resulting in false-positives. ${ }^{27}$

The visual-tactile examination method traditionally involved applying pressure with a sharp explorer unto stained pits or fissures to determine whether they felt "sticky." A "sticky" perception is thought to be indicative of the presence of caries. However, this is currently not accepted anymore for the assessment of noncavitated lesions and should be replaced by careful visual examination. ${ }^{28}$ This is due to the iatrogenic enamel defects produced by sharp explorers that convert the potentially remineralizable lesion into a cavity that is more vulnerable to caries progression. ${ }^{28,29}$ The latest trend in visual-tactile examination is to use a ball-ended WHO probe to evaluate the surface texture ${ }^{25}$ or discontinuity of the enamel surface $^{30}$ without pressure. Variations in diagnostic performance for this method have been reported in a systematic review ${ }^{23}$ with a wide range of sensitivity $(0.17-0.93)$ and a less varied range of specificity (0.71-1.00). The substantial variability for the visualtactile examination method has been postulated to be due to lack of information regarding the type and method of the explorer used and examiners' training and examination conditions for the tactile methods. ${ }^{23,31}$

\section{Dental Radiographs}

Loss of mineral content in enamel and dentine caries causes a decrease in the attenuation of the X-ray beam as it passes through the dental hard tissue, resulting in these lesions presenting as radiolucencies. ${ }^{32}$ For these radiolucencies to be visible, $40-60 \%$ of tooth demineralization must have occurred. ${ }^{33}$ Its use and frequency of its exposure should be justified in routine examination as the ionizing radiations are harmful to patients. In an attempt to decrease radiation exposure, fast radiographic films such as E- and F-speed films (Ultra-speed, Eastman Kodak Co, France) have been used. ${ }^{34}$ This was then followed by the introduction of digital radiography where complementary metal oxide sensor (CMOS) or wireless sensors like phosphor storage plate (PSP) replaced physical films and the images stored digitally. ${ }^{25}$ Its detection performance for dental caries is reported to be similar to that of analog radiography. ${ }^{35}$ Digital radiography has the advantages of less radiation exposure for the patient, possibility of image enhancement, and data sharing. ${ }^{36}$ Numerous factors can impact the accuracy of radiography, such as exposure time, image processing, viewing conditions, training, and experience of the examiner. ${ }^{37}$

Radiography with visual examination is the most common and routine diagnostic technique for caries detection. ${ }^{38}$ Out of all the dental radiography techniques, bitewing radiography is the 
most widely used method for the detection of dental caries. ${ }^{25}$ This technique is found to be sensitive in detecting caries that is well advanced into dentin but not favorable in detecting noncavitated fissure caries. ${ }^{39,40}$ Evidences suggested higher specificity (0.59$0.90)$ than sensitivity $(0.14-0.38)$ for detection of noncavitated fissure caries, meaning false-negative diagnosis is highly likely to occur. ${ }^{41}$ This is mainly due to the projection of the complicated three-dimensional occlusal enamel into a two-dimensional image, resulting in the overlapping of structures and loss of subtle diagnostic information on early fissure lesions. ${ }^{32}$

\section{Nonoptical Methods}

\section{Electrical Conductance and Impedance Methods}

The electrical conductance/impedance method utilizes the change in electrical conductivity to differentiate the sound enamel from carious lesions. Enamel demineralization results in porosities that are filled with water and ions from saliva resulting in the formation of conductive pathways for electrical transmission. The increased ionic content in the pores leads to increased electrical conductivity, or, conversely, increased porosity leads to decreased electrical resistance or impedance. ${ }^{42}$

One of the most investigated electrical resistance measurement devices is the electric caries monitor (ECM). It measures the bulk resistance of the tooth and works on a single fixed-frequency current. The ECM device can be used in two different modes, that is, the site-specific or surface-specific mode. In the site-specific mode, the probe is used with a coaxial airflow to dry the tissue around the probe and to prevent current leakage. In the surface-specific mode, however, the airflow is turned off and a medium, such as a toothpaste, is applied on the surface. ${ }^{43}$

In a systematic review conducted by Gomez et al., ${ }^{41}$ its sensitivity in detecting noncavitated fissure caries in permanent teeth was found to be 0.63 and specificity was 0.87 . Electrical conductance measurement is known to be affected by many factors such as pore volume and depth, surface area, enamel thickness, hydration, temperature, and the concentration of ions within the saliva. ${ }^{43,44}$ Moreover, presence of stain has also been identified as one of the major confounding factors when using this technique on the occlusal pits and fissures. ${ }^{45}$ Another issue of using this technique is its reproducibility variation, which ranges from 0.53 to 0.92 for the site-specific method and from 0.55 to 0.89 for the surface-specific method, ${ }^{44}$ possibly due to inconsistent placement of the probe and incomplete contact with the tooth surface. ${ }^{46}$ In lieu of this, it is not surprising that in a systematic review conducted by Gomez et al., ${ }^{41}$ the strength of evidence for detection of noncavitated lesions using ECM was rated as only fair, with mean quality score of 50.7 (ranged from 40 to 60), on a scale of 100 .

In an attempt to improve the performance of this measurement technique, electrical impedance spectroscopy (EIS) was proposed. It works on the basic principal that materials have different electrical responses at different frequencies. Using multiplefrequency measurements, EIS was hypothesized to be able to determine more accurately the various parameters that demonstrate these differences. ${ }^{43}$ The CarieScan PRO ${ }^{\mathrm{TM}}$ is an EIS device that is commercially available relatively recently. To obtain a measurement, a tested area is air-dried and the sensor pushed with gentle pressure onto the area. A quantitative value between 0 and 100 is produced, representing increase in caries severity in an ascending order. Unal et al. ${ }^{47}$ investigated the diagnostic performance of CarieScan $\mathrm{PRO}^{\mathrm{TM}}$ in detecting noncavitated fissure caries in permanent teeth and observed that this method has moderate sensitivity $(0.72-0.74)$ but low specificity $(0.59-0.74)$. Another study by Teo et al. ${ }^{48}$ investigated the system in primary teeth both in vitro and in vivo and reported poor diagnostic performances. In this study, two manufacturer's cutoff limits at the $D_{1}$ threshold were used, that is, code 21 (caries limited to outer third of the enamel) and code 51 (caries limited to inner third of the enamel). Although high sensitivity was observed at code 21 and code 51 , respectively, under in vivo and in vitro conditions $(0.93$, $0.72),(0.97,0.72)$, specificity was negligible $(0.00,0.22)$ to low $(0.04$, 0.50 ). Since the device is designed to assess initial caries lesions, poor specificity at both $\mathrm{D}_{1}$ cutoffs was concerning.

Low intraobserver repeatability was observed under in vitro settings with the kappa value ranging between 0.32 and 0.60 . A further drop was observed when the device was used under in vivo conditions with the kappa value between 0.13 and $0.30 .{ }^{48}$ Another study reported moderate kappa value (0.68) for the detection of noncavitated fissure caries in permanent teeth. ${ }^{47}$ This was attributed to the poor handling of the tip that comprises of a bundle of inflexible wires that is difficult to be used repeatedly on a small area. ${ }^{49}$ Hence, based on current available evidences, CarieScan PRO is not recommended for caries detection in primary teeth ${ }^{48}$ or permanent teeth. ${ }^{47,49}$

\section{Optical Methods}

\section{Fiber-optic Transillumination}

The FOTI method uses high-intensity white light in the visible range spectra $(400-700 \mathrm{~nm})$ to illuminate the tooth and to increase the contrast between the healthy and diseased enamel. The carious enamel scatters and absorbs more light compared to the sound enamel and therefore it appears dark whereas the sound enamel appears transparent. ${ }^{50}$ Dentin on the other hand appears brown to grey underneath the enamel. This distinct color contrast assists in the discrimination of enamel or dentin lesions. ${ }^{51}$

The method is not quantitative and diagnostic decisions are based on subjective outcomes discerned visually. Hence low reliability scores are expected due to subjective interpretation of the image by the operator. Furthermore, variability of the ambient light interferes with this method and hence it is recommended to have the dental operating lights switched off when using such devices. Furthermore, it is recommended that probe tips of less than $3 \mathrm{~mm}$ should be used to produce more focused beams. ${ }^{52}$

Several studies have reported high specificities (0.74-0.88) but varied sensitivities (0.21-0.96) for detection of fissure caries. ${ }^{41}$ However, these findings are based on inclusion of cavitated lesions. The performance of FOTI for the detection of fissure caries was reported to be similar to visual examination ${ }^{45}$ but greater than radiography. ${ }^{53}$ Bader et al. ${ }^{23}$ and Gomez et al. ${ }^{41}$ in systematic reviews for FOTI and digital FOTI (DIFOTI) found that, unlike for approximal caries, the strength of evidence of their detection performance for noncavitated fissure caries was weak due to variation in validation methods used, small number of examiners, and limited number of in vivo studies available.

This device has limitation for longitudinal monitoring of caries progression as the technique does not provide any quantitative information regarding the mineral loss or gain. ${ }^{54}$ In an attempt to overcome the variability problems and to enable monitoring of lesions, DIFOTI was introduced by replacing the human eye with a charge couple device (CCD) sensor. Reflected light was channeled through a mouthpiece to the CCD sensor and the image is 
displayed on a computer screen in real time and stored. ${ }^{55}$ However, quantification of the reflected light was still not possible. ${ }^{56}$

In light of the current literature, the diagnostic performance of FOTI and DIFOTI to detect noncavitated fissure caries lesion is limited and offers no better benefits than visual or radiographic methods. $^{25}$

\section{Near-infrared Light Transillumination}

Near-infrared (NIR) transillumination utilizes NIR light for the detection of enamel lesions and can differentiate extent of the lesion limited to the enamel from the ones that have reached the enamel dentin junction (EDJ). ${ }^{57}$ This technology works on the same mechanism of FOTI but the visible white light is replaced by NIR light (750-1500 nm), which has better and deeper penetration depth in the enamel. ${ }^{58}$ The enamel is highly transparent in the NIR range due to less scattering and absorption. The NIR technique is noninvasive, not confounded by stains, and can be used to map the horizontal extension of a caries lesion.

The KaVo DIAGNOCam is a commercially available device that uses the $780 \mathrm{~nm}$ wavelength and has two flexible extensions, one that transilluminates the tooth through periodontal tissues and another that captures the image of the tooth examined. ${ }^{59}$ This technique is best suited for proximal lesions and assessment of occlusal lesions that have reached the dentin enamel junction. ${ }^{60}$ An in vivo study concluded that DIAGNOCam was the most effective method for diagnosis of occlusal caries without cavitation in permanent molar teeth with 0.93 sensitivity, 0.69 specificity, and 0.60 correlation coefficient to histology. ${ }^{61}$

The performance of another NIR laser transillumination (wavelength of $808 \mathrm{~nm}$ ), by DMC Equipamentos (Sao Carlos, Brazil), showed moderate interrater reproducibility $(0.58)$ and sensitivity (0.68) but good specificity (0.85). ${ }^{62}$ Good specificity has been attributed to its ability to differentiate demineralization from other enamel changes like developmental defects, pigmentation, fluorosis, and calculus. ${ }^{58}$ The performance of NIR laser transillumination is comparable to a laser fluorescence system DIAGNOdent ${ }^{\circledR}$ pen and quantitative light-induced fluorescence methods and therefore is considered to be a valid and reliable technique for the detection of incipient occlusal caries on the permanent teeth. ${ }^{62}$

Besides the single-wavelength NIR transillumination described above, NIR multispectral imaging has been explored by Salsone et al. ${ }^{63}$ They showed that this technique, at specific wavelengths in the range of 1000-1700 nm, was able to quantify and map lesion distribution and severity at both enamel and dentin levels. They combined three spectral reflectance images to generate a quantitative lesion map of the tooth.

\section{Laser Fluorescence-based Methods}

\section{Laser-induced Fluorescence}

Light fluorescence (LF) is another method used for the detection and quantification of caries. ${ }^{64}$ In DIAGNOdent ${ }^{\circledR}$, monochromatic red laser light $(\lambda=655 \mathrm{~nm})$ is emitted unto the tooth surface and the back-scattered red fluorescence from the tooth ${ }^{65}$ is sensed. This technique responds to fluorescence radiated from proto-porphyrin, meso-porphyrin, and other metabolites of cariogenic bacteria ${ }^{64,66}$ present in the porosities of caries lesions. Numeric values between 0 (minimum fluorescence) and 99 (maximum fluorescence) show the degree of fluorescence with higher fluorescence indicating a more extensive lesion. ${ }^{64,67}$
There is wide variation reported in the literature for its performance in detecting fissure caries (cavitated lesions included), with sensitivity and specificity score ranging from 0.43 to 0.96 and 0.66 to 1.0 , respectively. ${ }^{41,59} \mathrm{~A}$ few studies have reported the effectiveness of DIAGNOdent ${ }^{\circledast}$ in detecting noncavitated occlusal caries on permanent teeth, and moderate sensitivity range of $0.66-0.75$, poor to excellent specificity range of $0.02-0.99$, and good intra/interexaminer reliability (kappa value of $0.87 / 0.82$ ) was observed. ${ }^{68}$ Another in vitro study in primary teeth reported that performance of DIAGNOdent ${ }^{\circledR}$ was not statistically significant when compared to visual assessment with low range of sensitivity (0.57-0.63) and high range of specificity (0.89-0.93). ${ }^{69}$

Moreover, it was also observed that DIAGNOdent ${ }^{\oplus}$ works best in detecting advanced carious lesions but it's not suitable for the detection of early lesions. ${ }^{64}$ It was reported in an in vitro study that DIAGNOdent ${ }^{\oplus}$ results did not correlate well [Pearson correlation coefficient (0.21)] with the depth of incipient occlusal caries. ${ }^{70}$

Since the fundamental basis of DIAGNOdent ${ }^{\circledR}$ is registering the presence of porphyrin fluorescence and not mineral content of the enamel structure, high false-positive readings ${ }^{64,70}$ and poor correlation with the mineral content are expected. This phenomenon is confounded by stain, plaque, and calculus commonly present in pits and fissures. ${ }^{65,71}$ Gomez et al. reported the quality of evidence of DIAGNOdent ${ }^{\circledR}$ for the detection of noncavitated fissure caries as poor ${ }^{41}$ and another systematic review on DIAGNOdent ${ }^{\oplus 72}$ draws the conclusion that this tool is to be used with caution due to the high likelihood of false-positive diagnosis.

\section{Quantitative Light-induced Fluorescence}

Quantitative light-induced fluorescence (QLF) involves the excitation of the tooth with blue light at a wavelength of $370 \mathrm{~nm}$, which results in the emanation of yellow-green fluorescence by fluorophores that are present within the EDJ. Demineralized areas of the enamel appear dark on a green fluorescence background. This is due to increased scattered light by the porous demineralized area resulting in less light reaching the EDJ and also less fluorescence reaching the surface from the EDJ. ${ }^{73}$ The difference in fluorescence between the sound and demineralized enamel can be quantified ${ }^{74}$ and used to monitor lesion progression over time. ${ }^{75,76}$ Although this technique has been proven to be able to monitor early enamel lesions on the smooth surface, ${ }^{77}$ limited literature is available on its utility for noncavitated caries detection. ${ }^{41,75}$ Due to small number of studies reported in the literature, Gomez et al. concluded the strength of evidence for detection of noncavitated fissure caries using QLF was poor. ${ }^{41}$

There are numerous confounders reported while using the QLF device. The presence of stain is one of the confounders resulting in signal loss indicating increased mineral loss and lesion progression. ${ }^{59}$ Furthermore, hydration of the lesion and inadequate reconstruction of sound fluorescence values may also confound the findings, decreasing the specificity. ${ }^{59,74}$ The current evidence for QLF to be used as a stand-alone method in detection of early fissure caries in every day practice is yet to be established. It was previously recommended that it is used in combination with ICDAS to benefit from the high sensitivity of QLF and high specificity of the visual assessment method. ${ }^{78}$

\section{Photothermal Radiometry and Modulated Luminescence}

Photothermal radiometry (PTR) is based on the optical irradiation absorption and generation of diffuse photon-density waves 
within a material or medium when it is irradiated by a modulated lower-power laser beam $(\sim \mathrm{mW})$. The diffuse photon-density waves (optical) would in turn be converted to thermal energy and emitted as oscillatory thermal waves, usually less than $1^{\circ} \mathrm{C}$ in magnitude. These waves are readily picked up by infrared sensors and carry subsurface information in the form of a spatially damped temperature depth integral. Modulated luminescence (LUM) is used as a complementary signal channel to PTR to monitor the opticalto-radiative energy conversion, thereby assisting interpretation of signals in the form of physical processes involving optical and thermal parameters of enamel. ${ }^{79}$ The combination of PTR and LUM amplitude and phase signals provides four sensitive channels to indirectly assess the physical condition and the state of health of teeth. ${ }^{80}$

The Canary System ${ }^{\circledR}$ is a commercially available system based on PTM/LUM technology. Using a proprietary algorithm, it converts PTR/LUM signatures into a Canary number on a scale from 0 to 100 with lower numbers suggesting healthy enamel and higher numbers indicate the presence of cracks and caries. For the detection of early fissure caries, it has shown very good sensitivity $(0.81)$ and specificity $(0.87)$ at the $D_{2}$ threshold. ${ }^{81}$ Another in vitro study that investigated its detection performance on artificial demineralized and remineralized lesions on the enamel and root surfaces concluded that it is sensitive to early changes in the enamel and showed good correlation with transverse microradiography (TMR). ${ }^{82}$ A multicenter clinical study concluded that PTR/LUM is safe for clinical application and is able to distinguish healthy from carious tooth structure on the occlusal surface with linear correlation $\left(R^{2}\right.$ $=0.92$ ) between the Canary numbers and ICDAS assessments. ${ }^{83}$ However, it was suggested that this method needs further research to identify suitable clinical thresholds that are relevant to treatment decision making. ${ }^{84}$

\section{Optical Coherence Tomography}

Optical coherence tomography (OCT) is a method that utilizes NIR light source between $850 \mathrm{~nm}$ and $1300 \mathrm{~nm}$ to obtain highquality cross-sectional images noninvasively. The light source is used in combination with a spectrometer to split the interference signal into single wavelengths. After Fourier transformation of the signal, a depth profile of the backscattered light perpendicular to the object surface is generated (A-scan). Point-by-point scan by the OCT beam across a sample produces a 2-D cross-sectional image (B-scan), and a series of these stacked 2-D cross-sections creates a 3-D image. The optical scattering properties of the enamel and dentine change when they are demineralized and a strong correlation between mineral loss and scattering coefficient increase has been demonstrated. ${ }^{50}$ Excellent agreement (Pearson correlation coefficient of 0.85 ) was found between the increase of backscattered light and lesion severity for occlusal lesions. ${ }^{85}$ However, false-positive results have been reported due to the strong surface specular reflectivity of the enamel that confounds backscattering increase caused by demineralization. Polarizationsensitive (PS)-OCT has been shown to eliminate this effect by integrating only the reflectivity of the orthogonal polarization (perpendicular axis) and, as a result, provide better resolution of the immediate subsurface zone. ${ }^{86}$

Depending on the application, detection of caries with OCT can be either quantitative or binary (i.e., absent or present). Quantitative measurements are usually in the form of outcome measures derived from the backscattered intensity depth profiles
(A-scans) and integrated intensity is one of the most commonly used outcome measure. Ngaotheppitak et al. ${ }^{86}$ have demonstrated a strong correlation between integrated mineral loss and integrated light reflectivity increase in the early natural demineralized enamel. An in vivo study ${ }^{87}$ found significant difference in the integrated reflectivity between the healthy enamel and noncavitated fissure caries lesions.

OCT B-scans on the other hand have been used by researchers to determine the presence or absence of caries visually. Three such studies ${ }^{88-90}$ investigated the detection performance of OCT for noncavitated fissure caries and unanimously reported high sensitivity (0.95-0.98) but varied specificity (0.39-0.95). The higher specificity (0.95) observed by Zain et al. when compared to Gomez et al.'s and Shimada et al.'s studies $(0.39$ and 0.75 , respectively) was attributed to the application of clearly described interpretation criteria to differentiate bulk backscattering (due to demineralization) from surface backscattering (due to specular reflection). The interpretation criteria were developed based upon the location, depth, and pattern of the increased intensity. ${ }^{90}$

The application of OCT has found its trail into clinical diagnostics in particular to detect noncavitated fissure caries because of its ability to acquire high-resolution cross-sectional image of a scanned area and its insensitiveness to staining. The high cost of the system is the main limitation of its application into daily clinical practice.

\section{Conclusion}

The rational of diagnosis of noncavitated caries lesion is to be able to provide timely secondary preventive treatment plan to preserve the tooth structure as much and as long as possible. Hence, its diagnosis should not be delivering the detection step alone. It should ideally comprise of both detection and severity measurement in the form of lesion depth, demineralization severity, and mineral density distribution (i.e., presence of a superficial hypermineralized layer). A combination of these information is essential for clinicians to make informed decisions about the management and prognosis of the disease process.

Based on the current evidences and reviews, except for OCT, most devices are only able to detect and determine either lesion depth or demineralization severity but not both. Hence, in order to be able to gather all necessary information to formulate a treatment plan for noncavitated fissure caries and monitor its efficacy, routine systematic visual assessment will need to be supplemented by another quantification-enabled detection device that had demonstrated reasonably high sensitivity and specificity. Current evidences seem to indicate that PTR, NIR transillumination, and OCT are systems that had demonstrated such capabilities.

\section{References}

1. Kassebaum NJ, Bernabe E, Dahiya M, et al. Global burden of untreated caries: a systematic review and metaregression. J Dent Res 2015;94(5):650-658. DOI: 10.1177/0022034515573272.

2. Kidd EA, Fejerskov O. What constitutes dental caries? histopathology of carious enamel and dentin related to the action of cariogenic biofilms. J Dent Res 2004;83(Spec No C):C35-C38. DOI: 10.1177/154405910408301s07.

3. Featherstone JD. The continuum of dental caries-evidence for a dynamic disease process. J Dent Res 2004;83(Spec No C):C39-C42. DOI: $10.1177 / 154405910408301$ s08. 
4. Marcenes W, Kassebaum NJ, Bernabe E, et al. Global burden of oral conditions in 1990-2010: a systematic analysis. J Dent Res 2013;92(7):592-597. DOI: 10.1177/0022034513490168.

5. Zero DT. Dental caries process. Dent Clin North Am 1999;43(4): 635-664.

6. Mejare I, Stenlund H,Zelezny-Holmlund C. Caries incidence and lesion progression from adolescence to young adulthood: a prospective 15-year cohort study in Sweden. Caries Res 2004;38(2):130-141. DOI: 10.1159/000075937.

7. Ismail Al, Tellez M, Pitts NB, et al. Caries management pathways preserve dental tissues and promote oral health. Community Dent Oral Epidemiol 2013;41(1):e12-e40. DOI: 10.1111/cdoe.12024.

8. Amaechi BT. Emerging technologies for diagnosis of dental caries: the road so far. J Appl Phys 2009;105(10):102047. DOI: 10.1063/1. 3116632.

9. Makhija SK, Gilbert GH, Funkhouser E, et al. Characteristics, detection methods and treatment of questionable occlusal carious lesions: findings from the national dental practice-based research network. Caries Res 2014;48(3):200-207. DOI: 10.1159/000354841.

10. Pitts N, Stamm J. International consensus workshop on caries clinical trials (ICW-CCT) - final consensus statements: agreeing where the evidence leads. J Dent Res 2004;83(suppl 1):C125-C128.

11. Brunelle J. Oral health of United States children. The national survey of dental caries in US school children; 1986-87. National and Regional Findings US Department of Health and Human Services; 1989.

12. Carvalho JC. Caries process on occlusal surfaces: evolving evidence and understanding. Caries Res 2014;48(4):339-346. DOI: 10.1159/000356307.

13. Baelum V, Fejerskov O, Nyvad B. Dental caries: the disease and its clinical management. Blackwell Munksgaard; 2008.

14. Jablonski-Momeni A, Ricketts DN, Weber K, et al. Effect of different time intervals between examinations on the reproducibility of ICDAS-II for occlusal caries. Caries Res 2010;44(3):267-271. DOI: 10.1159/000314674.

15. Golafshani N. Understanding reliability and validity in qualitative research. The qualitative report 2003;8(4):597-606.

16. Leeflang MM, Deeks JJ, Takwoingi Y, et al. Cochrane diagnostic test accuracy reviews. Syst Rev 2013;2:82. DOI: 10.1186/2046-4053-2-82.

17. WHO A guide to oral health epidemiological investigations. Geneva 1979.

18. Gimenez T, Piovesan C, Braga MM, et al. Visual Inspection for caries detection: a systematic review and meta-analysis. J Dent Res 2015;94(7):895-904. DOI: 10.1177/0022034515586763.

19. Schwendicke F, Tzschoppe M, Paris S. Radiographic caries detection: a systematic review and meta-analysis. J Dent 2015;43(8):924-933. DOI: 10.1016/j.jdent.2015.02.009.

20. Domejean S, Rongier J, Muller-Bolla M. Detection of occlusal carious lesion using the SoproLife ${ }^{\circledR}$ camera: a systematic review. J Contemp Dent Pract 2016;17(9):774-779. DOI: 10.5005/jp-journals-100241928.

21. Ekstrand KR, Gimenez T, Ferreira FR, et al. The international caries detection and assessment system - ICDAS: a systematic review. Caries Res 2018;52(5):406-419. DOI: 10.1159/000486429.

22. Gimenez T, Braga MM, Raggio DP, et al. Fluorescence-based methods for detecting caries lesions: systematic review, meta-analysis and sources of heterogeneity. PLoS ONE 2013;8(4):e60421. DOI: 10.1371/ journal.pone.0060421.

23. Bader JD, Shugars DA, Bonito AJ. A systematic review of the performance of methods for identifying carious lesions. J Public Health Dent 2002;62(4):201-213. DOI: 10.1111/j.1752-7325.2002. tb03446.x.

24. Ekstrand KR, Ricketts DN, Kidd EA. Occlusal caries: pathology, diagnosis and logical management. Dent Update 2001;28(8):380-387. DOI: 10.12968/denu.2001.28.8.380.

25. Braga MM, Mendes FM, Ekstrand KR. Detection activity assessment and diagnosis of dental caries lesions. Dent Clin North Am 2010;54(3):479-493. DOI: 10.1016/j.cden.2010.03.006.
26. Ismail Al, Sohn W, Tellez M, et al. The international caries detection and assessment system (ICDAS): An integrated system for measuring dental caries. Community Dent Oral Epidemiol 2007;35(3):170-178. DOI: 10.1111/j.1600-0528.2007.00347.x.

27. Jablonski-Momeni A, Stachniss V, Ricketts DN, et al. Reproducibility and accuracy of the ICDAS-II for detection of occlusal caries in vitro. Caries Res 2008;42(2):79-87. DOI: 10.1159/000113160.

28. Kuhnisch J, Dietz W, Stosser L, et al. Effects of dental probing on occlusal surfaces-a scanning electron microscopy evaluation. Caries Res 2007;41(1):43-48. DOI: 10.1159/000096104.

29. Ekstrand K, Qvist V, Thylstrup A. Light microscope study of the effect of probing in occlusal surfaces. Caries Res 1987;21(4):368-374. DOI: 10.1159/000261041.

30. WHO. Oral health surveys: basic methods; 1997.

31. Ismail Al. Visual and visuo-tactile detection of dental caries. J Dent Res 2004;83(Spec No C):C56-C66. DOI: 10.1177/154405910408301s12.

32. Neuhaus KW, Lussi A. Carious lesion diagnosis: methods, problems, thresholds. Monogr Oral Sci 2018;27:24-31.

33. Yang J, Dutra V. Utility of radiology, laser fluorescence, and transillumination. Dent Clin North Am 2005;49(4):739-752. DOI: 10.1016/j.cden.2005.05.010, vi.

34. Thunthy $\mathrm{KH}$, Ireland EJ. A comparison of the visibility of caries on Kodak F-speed (insight) and D-speed (ultra-speed) films. LDA J 2001;60(2):31-32.

35. Syriopoulos K, Sanderink GC, Velders XL, et al. Radiographic detection of approximal caries: a comparison of dental films and digital imaging systems. Dentomaxillofac Radiol 2000;29(5):312-318. DOI: 10.1038/ sj.dmfr.4600553.

36. Dove SB. Radiographic diagnosis of dental caries. J Dent Educ 2001;65(10):985-990.

37. Diniz MB, Rodrigues JA, Neuhaus KW, et al. Influence of examiner's clinical experience on the reproducibility and accuracy of radiographic examination in detecting occlusal caries. Clin Oral Investig 2010;14(5):515-523. DOI: 10.1007/s00784-009-0323-z.

38. Abesi F, Mirshekar A, Moudi E, et al. Diagnostic accuracy of digital and conventional radiography in the detection of non-cavitated approximal dental caries. Iran J Radiol 2012;9(1):17-21. DOI: 10.5812/ iranjradiol.6747.

39. Machiulskiene V, Nyvad B, Baelum V. Comparison of diagnostic yields of clinical and radiographic caries examinations in children of different age. Eur J Paediatr Dent 2004;5(3):157-162.

40. Ricketts DN, Kidd EA, Smith BG, et al. Clinical and radiographic diagnosis of occlusal caries: a study in vitro. J Oral Rehabil 1995;22(1):15-20. DOI: 10.1111/j.1365-2842.1995.tb00205.x.

41. Gomez J, Tellez M, Pretty IA, et al. Non-cavitated carious lesions detection methods: a systematic review. Community Dent Oral Epidemiol 2013;41(1):55-66. DOI: 10.1111/cdoe.12021.

42. Ricketts DNJ, Kidd EAM, Wilson RF. Electronic diagnosis of occlusal caries in vitro: adaptation of the technique for epidemiological purposes. Community Dent Oral Epidemiol 1997;25(3):238-241. DOI: 10.1111/j.1600-0528.1997.tb00933.x.

43. Longbottom C, Huysmans MC. Electrical measurements for use in caries clinical trials. J Dent Res 2004;83(Spec No C):C76-C79. DOI: 10.1177/154405910408301s15.

44. Neuhaus KW, Longbottom C, Ellwood R, et al. Novel lesion detection aids. Monogr Oral Sci 2009;21:52-62.

45. Cortes D, Ellwood R, Ekstrand K. An in vitro comparison of a combined $\mathrm{FOTI} /$ visual examination of occlusal caries with other caries diagnostic methods and the effect of stain on their diagnostic performance. Caries Res 2003;37(1):8-16. DOI: 10.1159/000068230.

46. Huysmans $M C$, Longbottom $C$. The challenges of validating diagnostic methods and selecting appropriate gold standards. J Dent Res 2004;83(Spec No C):C48-C52. DOI: 10.1177/154405910408301s10.

47. Unal M, Kockanat A, Guler S, et al. Diagnostic performance of different methods in detecting incipient non-cavitated occlusal caries lesions in permanent teeth. J Clin Pediatr Dent 2019;43(3):173-179. DOI: 10.17796/1053-4625-43.3.5. 
48. Teo TK-Y, Ashley PF, Louca C. An in vivo and in vitro investigation of the use of ICDAS, DIAGNOdent pen and CarieScan PRO for the detection and assessment of occlusal caries in primary molar teeth. Clin Oral Investig 2013; 1-8.

49. Mortensen $D$, Hessing-Olsen I, Ekstrand KR, et al. In-vivo performance of impedance spectroscopy, laser fluorescence, and bitewing radiographs for occlusal caries detection. Quintessence Int 2018;49(4):293-299.

50. Darling CL, Huynh GD, Fried D. Light scattering properties of natural and artificially demineralized dental enamel at $1310 \mathrm{~nm}$. J Biomed Opt 2006;11(3):034023. DOI: 10.1117/1.2204603.

51. Gomez J. Detection and diagnosis of the early caries lesion. BMC Oral Health 2015;15(Suppl 1):S3. DOI: 10.1186/1472-6831-15S1-S3.

52. Hogan R, Pretty IA, Ellwood RP. Fibre-optic transillumination: FOTI. In: Ferreira Zandona, Andrea, Longbottom, et al. Detection and Assessment of Dental Caries Springer, Cham; 2019. pp. 139-150.

53. Cortes DF, Ekstrand KR, Elias-Boneta AR, et al. An in vitro comparison of the ability of fibre-optic transillumination, visual inspection and radiographs to detect occlusal caries and evaluate lesion depth. Caries Res 2000;34(6):443-447. DOI: 10.1159/000016621.

54. Choo-Smith LP, Dong CC, Cleghorn B, et al. Shedding new light on early caries detection. Tex Dent J 2009;126(2):152-159.

55. Schneiderman A, Elbaum M, Shultz $T$, et al. Assessment of dental caries with digital imaging fiber-optic transillumination (DIFOTI): in vitro study. Caries Res 1997;31(2):103-110. DOI: 10.1159/ 000262384.

56. Manton DJ. Diagnosis of the early carious lesion. Aust Dent J 2013;58(Suppl 1):35-39. DOI: 10.1111/adj.12048.

57. Abdelaziz M, Krejci I, Perneger T, et al. Near infrared transillumination compared with radiography to detect and monitor proximal caries: a clinical retrospective study. J Dent 2018;70:40-45. DOI: 10.1016/ j.jdent.2017.12.008.

58. Fried D, Featherstone JD, Darling $C L$, et al. Early caries imaging and monitoring with near-infrared light. Dent Clin North Am 2005;49(4):771-793. DOI: 10.1016/j.cden.2005.05.008, vi.

59. Pretty IA, Ekstrand KR. Detection and monitoring of early caries lesions: A review. Eur Arch Paediatr Dent 2016;17(1):13-25. DOI: 10.1007/s40368-015-0208-6.

60. Sochtig F, Hickel R, Kuhnisch J. Caries detection and diagnostics with near-infrared light transillumination: clinical experiences. Quintessence Int 2014;45(6):531-538. DOI: 10.3290/j.qi.a31533.

61. Tassoker M, Sener S, Karabekiroglu S. Occlusal caries detection and diagnosis using visual ICDAS criteria, laser fluorescence measurements and near-infrared light transillumination images. Med Princ Pract 2019. DOI: 10.1159/000501257.

62. Bussaneli DG, Restrepo M, Boldieri T, et al. Assessment of a new infrared laser transillumination technology $(808 \mathrm{nM})$ for the detection of occlusal caries-an in vitro study. Lasers Med Sci 2015;30(7): 1873-1879. DOI: 10.1007/s10103-014-1704-3.

63. Salsone S, Taylor A, Gomez J, et al. Histological validation of nearinfrared reflectance multispectral imaging technique for caries detection and quantification. J Biomed Opt 2012;17(7):076009. DOI: 10.1117/1.JBO.17.7.076009.

64. Lussi A, Hibst R, Paulus R. DIAGNOdent: An optical method for caries detection. J Dent Res 2004;83(Spec No C):C80-C83. DOI: 10.1177/154405910408301s16.

65. Lussi A, Imwinkelried S, Pitts N, et al. Performance and reproducibility of a laser fluorescence system for detection of occlusal caries in vitro. Caries Res 1999;33(4):261-266. DOI: 10.1159/000016527.

66. Sailer R, Paulus R, Hibst R. Analysis of carious lesions and subgingival calculi by fluorescence spectroscopy. Caries Res 2001;35(4): 267.

67. Gostanian HV, Shey Z, Kasinathan C, et al. An in vitro evaluation of the effect of sealant characteristics on laser fluorescence for caries detection. Pediatr Dent 2006;28(5):445-450.
68. Achilleos EE, Rahiotis C, Kakaboura A, et al. Evaluation of a new fluorescence-based device in the detection of incipient occlusal caries lesions. Lasers Med Sci 2013;28(1):193-201. DOI: 10.1007/s10103012-1111-6.

69. Attrill DC, Ashley PF. Occlusal caries detection in primary teeth: a comparison of DIAGNOdent with conventional methods. Br Dent J 2001;190(8):440-443. DOI: 10.1038/sj.bdj.4800998.

70. Abrams SH, Sivagurunathan KS, Silvertown JD, et al. Correlation with caries lesion depth of the canary system, DIAGNOdent and ICDAS II. Open Dent J 2017;11:679-689. DOI: 10.2174/1874210601711010679.

71. Shi XQ, Welander U, Angmar-Mansson B. Occlusal caries detection with KaVo DIAGNOdent and radiography: an in vitro comparison. Caries Res 2000;34(2):151-158. DOI: 10.1159/000016583.

72. Bader JD, Shugars DA. A systematic review of the performance of a laser fluorescence device for detecting caries. J Am Dent Assoc 2004;135(10):1413-1426. DOI: 10.14219/jada.archive.2004.0051.

73. Pretty IA. Caries detection and diagnosis: novel technologies. J Dent 2006;34(10):727-739. DOI: 10.1016/j.jdent.2006.06.001.

74. Angmar-Mansson B, ten Bosch JJ. Quantitative light-induced fluorescence (QLF): a method for assessment of incipient caries lesions. Dentomaxillofac Radiol 2001;30(6):298-307. DOI: 10.1038/ sj.dmfr.4600644.

75. Karlsson L. Caries detection methods based on changes in optical properties between healthy and carious tissue. Int J Dent 2010;2010:270729.

76. van der Veen $\mathrm{MH}$, de Josselin, de Jong E. Application of quantitative light-induced fluorescence for assessing early caries lesions. Monogr Oral Sci 2000;17:144-162.

77. Tranaeus S, Al-Khateeb S, Bjorkman S, et al. Application of quantitative light-induced fluorescence to monitor incipient lesions in cariesactive children. A comparative study of remineralisation by fluoride varnish and professional cleaning. Eur J Oral Sci 2001;109(2):71-75. DOI: 10.1034/j.1600-0722.2001.00997.x.

78. Zandona AF, Santiago E, Eckert G, et al. Use of ICDAS combined with quantitative light-induced fluorescence as a caries detection method. Caries Res 2010;44(3):317-322. DOI: 10.1159/000317294.

79. Garcia JA, Mandelis A, Abrams SH, et al. Photothermal radiometry and modulated luminescence: applications for dental caries detection. Handbook of biophotonics 2013; 1047-1052.

80. Hellen A, Mandelis A, Finer Y, et al. Quantitative evaluation of the kinetics of human enamel simulated caries using Photothermal radiometry and modulated luminescence. J Biomed Opt 2011;16(7):071406. DOI: 10.1117/1.3564909.

81. Jeon RJ, Han C, Mandelis A, et al. Diagnosis of pit and fissure caries using frequency-domain infrared photothermal radiometry and modulated laser luminescence. Caries Res 2004;38(6):497-513. DOI: 10.1159/000080579.

82. Jeon RJ, Hellen A, Matvienko A, et al. In vitro detection and quantification of enamel and root caries using infrared Photothermal radiometry and modulated luminescence. J Biomed Opt 2008;13(3):034025. DOI: 10.1117/1.2942374.

83. Silvertown JD, Abrams SH, Sivagurunathan KS, et al. Multi-centre clinical evaluation of photothermal radiometry and luminescence correlated with international benchmarks for caries detection. Open Dent J 2017;11:636-647. DOI: 10.2174/1874210601711010636.

84. Jallad $M$, Zero $D$, Eckert $G$, et al. In vitro detection of occlusal caries on permanent teeth by a visual, light-induced fluorescence and photothermal radiometry and modulated luminescence methods. Caries Res 2015;49(5):523-530. DOI: 10.1159/000437214.

85. Ngaotheppitak P, Darling CL, Fried D, et al. PS-OCT of occlusal and interproximal caries lesions viewed from occlusal surfaces. Lasers in Dentistry XII. 2006;6137:L1370.

86. Ngaotheppitak $\mathrm{P}$, Darling $\mathrm{CL}$, Fried D. Measurement of the severity of natural smooth surface (interproximal) caries lesions with polarization sensitive optical coherence tomography. Lasers Surg Med 2005;37(1):78-88. DOI: 10.1002/Ism.20169. 
87. Louie $T$, Lee $C, H s u$ D, et al. Clinical assessment of early tooth demineralization using polarization sensitive optical coherence tomography. Lasers Surg Med 2010;42(10):738-745. DOI: 10.1002/ Ism.21013.

88. Gomez J, Zakian C, Salsone S, et al. In vitro performance of different methods in detecting occlusal caries lesions. J Dent 2013;41(2): 180-186. DOI: 10.1016/j.jdent.2012.11.003.
89. Shimada Y, Sadr A, Burrow MF, et al. Validation of swept-source optical coherence tomography (SS-OCT) for the diagnosis of occlusal caries. J Dent 2010;38(8):655-665. DOI: 10.1016/j.jdent.2010. 05.004.

90. Zain E, Zakian CM, Chew HP. Influence of the loci of non-cavitated fissure caries on its detection with optical coherence tomography. J Dent 2018;71:31-37. DOI: 10.1016/j.jdent.2018.01.009. 